\title{
The Thermal Hydraulic Performance of Wavy PCHE with Different Materials and Geometric Parameters
}

\author{
Yunzhu Li ${ }^{1, a}$, Yonghui Xie ${ }^{1}$ and Di Zhang ${ }^{1}$ \\ ${ }^{1}$ Shaanxi Engineering Laboratory of Turbomachinery and Power Equipment, School of Energy and Power Engineering, Xi'an Jiaotong \\ University, Xi'an, China
}

\begin{abstract}
The printed circuited heat exchanger (PCHE) contain several different channel configurations, such as straight channel, zigzag channel and wavy channel. The wavy channel has better thermal performance than the straight channel and better hydraulic performance than the zigzag channel. This paper explores the thermal hydraulic performance of wavy channel PCHE. The numerical analysis of the PCHE in different materials and geometric parameters are conducted by computational fluid dynamics (CFD) tool. The materials applied in simulations involve Alloy617, Titanium Grade 3, Carlson 2205, UNS S30400 and Sandvik 253A. The results show that the materials have little effect on the thermal-hydraulic performance. The geometric parameters include channel degree varying from $10^{\circ}$ to $50^{\circ}$, channel amplitude varying from $1 \mathrm{~mm}$ to $5 \mathrm{~mm}$ and the radium of hot/cold channel varying from $0.4 \mathrm{~mm}$ to $2.0 \mathrm{~mm}$. It is found that the larger radium of hot channel results out the lower Nusselt number and lower fanningfriction factor while the higher radium of cold channel produces the higher Nusselt number and lower fanning-friction factor. The larger channel amplitude indicates the higher fanning-friction factor and lower Nusselt number. The larger channel degree indicates the higher fanning-friction factor, and higher Nusselt number.
\end{abstract}

\section{Introduction}

The PCHEs are more and more popular in many areas, including nuclear energy, electronic cooling and ocean engineering. Compared with the conventional shell and tube heat exchanger, the PCHEs can reduce $85 \%$ weight and only take place one third room. Besides, the diffusion bonding technique allows the PCHEs enduring a wide range of temperature and pressure. Due to plenty of advantages, researchers pay much attentions on PCHE and make abundant studies around the thermal-hydraulic performance. Justin et al.[1] have investigated the thermal and hydraulic performance for straight channel PCHEs in Very High Temperature Reactors(VHTRs). Kim et al.[2] proposed a newly PCHE based and explored the local friction factor with different hydraulic diameters and inclination degrees in lower Reynolds. Ting $\mathrm{Ma}$ et al.[3] identifies the local thermal-hydraulic performance of zigzag channel PCHE at high temperature of $900^{\circ} \mathrm{C}$. The study implies that the heat transfer enhancement with inclined angles should consider the operation conditions. Jeon et al.[4] outlined an innovative type of PCHE, the heterogeneous and considered the effect of channel sizes, the spacing between channels and the channel crosssectional shape on the thermal-hydraulic performance. Aneesh et al.[5] clarified the heat transfer rate and thermo-hydraulic performance of trapezoidal, sinusoidal and triangular channel PCHE, and they expounded the trapezoidal channel have the highest heat transfer rate and

\footnotetext{
a Corresponding author: author@e-mail.org
}

optimal thermo-hydraulic performance. The helium test loop and numerical simulations were conducted by In Hun Kim et al.[6, 7], they obtained the fanning-friction factor and Nusselt number correlations with the operation condition parameters. Sung et al.[8] interpreted the effect of tangled channels on the thermal-hydraulic performance in PCHE with the Reynolds number at 1000 to 3000. Tsuzuki et al. $[9,10]$ proposed a new configuration PCHE with S-shaped fin configuration, and reported the heat transfer and pressure drop of S-shaped fin PCHE with different geometrics.

The academic community has extensively explored the thermal-hydraulic performance for PCHEs. However, little research has been conducted to show the effect of the materials and geometric parameters for the sinusoidal channel PCHE. The study explores thermal-hydraulic performance of sinusoidal channel PCHE with different materials and geometric parameters

\section{SYSTEM DESCRIPTION AND NUMERICAL MODEL}

The traditional PCHE system as illustrated in Figure 1 right contains a stack of photochemical etching planets with many semicircular fluid passages. The sinusoidal channel PCHEs are investigated and the reduced models are used in three-dimensional simulations. In this work, the radium of the hot channel and cold channel change from $0.4 \mathrm{~mm}$ to $2.0 \mathrm{~mm}$, the amplitude A ranges from 
$1 \mathrm{~mm}$ to $5 \mathrm{~mm}$ and the angle varies from $10^{\circ}$ to $50^{\circ}$ as illustrated in Figure1 left. The cold and hot SCO2 are utilized as the working fluid, the inlet temperature and the outlet pressure in cold fluid are set as $381 \mathrm{~K}$ and $8.5 \mathrm{MPa}$, while those in hot fluid are set as $553 \mathrm{~K}$ and $2.6 \mathrm{MPa}$ respectively.

In this work, the hexahedral mesh as shown in Figure 2 is applied by the ANSYS ICEM CFD, the first cell height is set as $0.02 \mathrm{~mm}$. The grid independence verification as shown in Table 1 is done to guaranteed accuracy. The results show that the solutions of the chose model has less than $1 \%$ different from the last model.

ANSYS FLUENT is used to numerical simulate the PCHEs and the finite volume method is taken to describe the governing equations as shown in Eqs. (1-3). These equations are the continuous equation, momentum equation and energy equation used for heat and mass transfer in fluid domain. Eq. 4 is the energy equation applied for the solid domain.
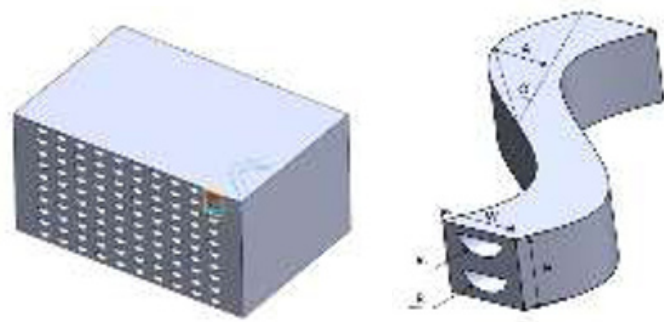

Figure 1. The configuration of PCHE.

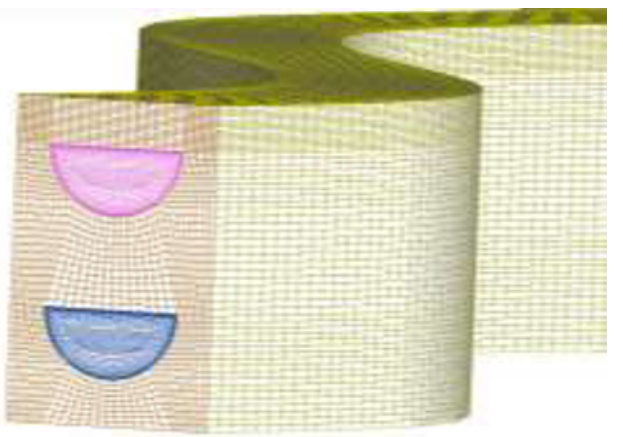

Figure 2. A small section of wavy PCHE for general mesh representation.

Table 1. Grid independence verification

\begin{tabular}{|c|c|c|c|c|c|}
\hline Model & $\begin{array}{c}\text { Mesh } \\
(104)\end{array}$ & $\begin{array}{c}\mathrm{T}_{\mathrm{h}, \text { out }} \\
(\mathrm{K})\end{array}$ & $\begin{array}{c}\text { Error } \\
(\%)\end{array}$ & $\begin{array}{c}\Delta \mathrm{p}_{\mathrm{c}} \\
(\mathrm{Pa})\end{array}$ & $\begin{array}{c}\text { Error } \\
(\%)\end{array}$ \\
\hline 1 & 160 & 424.34 & 1.41 & 3467 & 1.31 \\
\hline 2 & 309 & 420.16 & 0.41 & 3490 & 0.65 \\
\hline 3 & 442 & 419.59 & 0.28 & 3504 & 0.26 \\
\hline
\end{tabular}

$$
\frac{\partial\left(\rho u_{i}\right)}{\partial x_{i}}=0
$$

$$
\begin{gathered}
\rho \frac{\partial}{\partial u_{i}}\left(u_{i} u_{j}\right)=-\frac{\partial p}{\partial x_{i}}+\mu \frac{\partial}{\partial x_{i}}\left(\frac{\partial u_{j}}{\partial x_{i}}+\frac{\partial u_{i}}{\partial x_{j}}-\frac{2}{3} \delta_{i j} \frac{\partial u_{k}}{\partial x_{k}}\right) \\
\frac{\partial}{\partial x_{i}}\left[u_{i}(\rho E+p)\right]=\frac{\partial}{\partial x_{i}}\left[\left(k_{f}+k_{t}\right) \frac{\partial T}{\partial x_{i}}\right] \\
\frac{\partial}{\partial x_{i}}\left(k_{s} \frac{\partial T}{\partial x_{i}}\right)=0
\end{gathered}
$$

The $\mathrm{RNG} \mathrm{k}-\varepsilon$ model is adopted to model the turbulence. The mass flow inlet and pressure outlet boundary conditions are specified on the cold channel and hot channel correspondingly. The periodic boundary condition is applied on the up and down walls and the adiabatic boundary condition is set for the front walls, back walls and side walls. . The NIST real gas model is applied to estimate the thermal properties of the SCO2. The thermal-hydraulic characteristic considered include the heat transfer coefficient, Nusselt number and fanning friction factor as illustrated in Eqs.(5-8).

The hydraulic diameter of the channel is

$$
D_{h}=\frac{\pi R}{(\pi / 2+1)}
$$

where the $\mathrm{R}$ is the channel diameter. The heat transfer coefficient is described as followed

$$
h=\frac{q}{T_{b}-T_{w}}
$$

where the $T_{b}$ is the volume average temperature of fluid, $T_{w}$ is the area weighted temperature of the channel walls. The Nusselt number is shown as followed

$$
N u=\frac{h D_{h}}{\lambda}
$$

where the $\lambda$ is the heat conductivity of fluid. The fanning friction factor is expressed as followed

$$
f=\frac{\Delta p \cdot D_{\mathrm{h}}}{2 \rho L u_{\mathrm{in}}^{2}}
$$

where the $\Delta p$ is the pressure different between the inlet and outlet., $\rho$ is the fluid density, $L$ is the total length of channels and the $u_{i n}$ is the inlet velocity.

Fluent 16.0 provides many turbulent models to simulate the actual situations, including Standard $k-\varepsilon$, Realizable $k-\varepsilon$, RNG $k-\varepsilon$, Standard $k-\omega$, SST $k-\omega$. In this paper, the data in research[11] is taken as the standard, the boundary conditions are completely same and the physical model is basically consistent. The results showed in Table 3 demonstrated that the numerical model with $\mathrm{RNG} k-\varepsilon$ is closest to the standard. In this paper, the turbulent model of RNG $k-\varepsilon$ is chose as the calculate method. 
Table 3. Validation of different turbulent models.

\begin{tabular}{|c|c|c|c|}
\hline Variable & $\begin{array}{c}\text { Ref } \\
{[11]}\end{array}$ & $\begin{array}{c}\text { Realizable } \\
k-\varepsilon\end{array}$ & $\begin{array}{c}\text { Standard } \\
k-\omega\end{array}$ \\
\hline$N u$ & 69.8 & 78.9 & 94.8 \\
\hline error $_{N u}$ & 0 & 0.1304 & 0.3582 \\
\hline$f$ & 0.0513 & 0.0569 & 0.0608 \\
\hline error $_{f}$ & 0 & 0.1092 & 0.1852 \\
\hline Variable $^{2}$ & $\begin{array}{c}\text { Ref } \\
{[11]}\end{array}$ & $\begin{array}{c}\text { Standard } \\
\mathrm{k}-\varepsilon\end{array}$ & $\begin{array}{c}\mathrm{RNG} \\
\mathrm{k}-\varepsilon\end{array}$ \\
\hline $\mathrm{Nu}_{\mathrm{Nu}}$ & 69.8 & 76.2 & 73.6 \\
\hline error $_{\mathrm{Nu}}$ & 0 & 0.0917 & 0.0544 \\
\hline f $_{\text {error }}$ & 0.0513 & 0.0544 & 0.0544 \\
\hline
\end{tabular}

\section{Results and Discussion}

\subsection{Effect of Materials}

The Table 2 shows the properties of five different materials including Alloy617, Titanium Grade 3, Carlson 2205, UNS S30400 and Sandvik 253A. Under the same boundary conditions, the PCHEs have similar thermal and hydraulic performance as shown in Figure 2. Take the results with Alloy 617 as a standard, the maximum error of Nusselt number of hot fluid and cold fluid is $0.59 \%$ and $1.03 \%$, while the maximum error of Fanning friction factor is $3.54 \%$ and $1.93 \%$.

Table 2. The properties of five different materials.

\begin{tabular}{|c|c|c|c|c|}
\hline Number & Material & $\begin{array}{c}\text { Density } \\
(\mathrm{kg} / \mathrm{m} 3)\end{array}$ & $\begin{array}{c}\text { Specific } \\
\text { heat } \\
\text { capacity } \\
\left(\mathrm{J} / \mathrm{kg} \cdot{ }^{\circ} \mathrm{C}\right)\end{array}$ & $\begin{array}{c}\text { Thermal } \\
\text { conductivity } \\
(\mathrm{W} / \mathrm{m} \cdot \mathrm{K})\end{array}$ \\
\hline 1 & $\begin{array}{c}\text { Sandivk } \\
253 \mathrm{MA}\end{array}$ & 7800 & 0.540 & 16.000 \\
\hline 2 & $\begin{array}{c}\text { UNS } \\
\text { S30400 }\end{array}$ & 8000 & 0.500 & 17.525 \\
\hline 3 & $\begin{array}{c}\text { Titanium } \\
\text { Grade3 }\end{array}$ & 4500 & 0.560 & 18.100 \\
\hline 4 & $\begin{array}{c}\text { Carlson } \\
2205\end{array}$ & 7820 & 0.418 & 19.000 \\
\hline 5 & Alloy 617 & 9240 & 0.465 & 16.300 \\
\hline
\end{tabular}

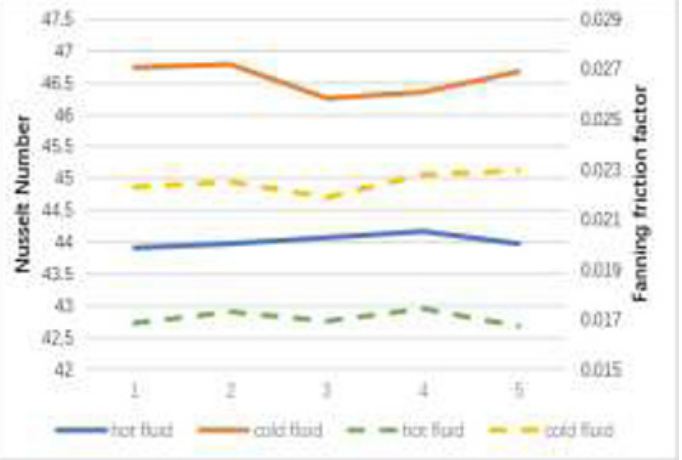

Figure 3. The effect of materials on the Nusselt number (denoted by solid lines) and fanning friction factor (denoted by dotted lines)

\subsection{Effect of Geometric Parameters}

Plenty of study about the effect of the hydraulic radium have been done, but the radium of hot channel equals to that of cold channel. In this work, the effect of hot and cold channel radium is investigated respectively.

Figure 4 shows the effect of the radium of hot channel on the Nusselt number and fanning friction factor. The results prove that the Nusselt number as well as the fanning friction factor decrease with the radium. It is obvious that the bigger the radium is the lower the velocity is, so that the pressure drop is relatively lower and the fanning friction factor declines. Moreover, the reduction of the heat transfer coefficient is much larger than increasement of hydraulic radium, which results out the lower Nusselt number.

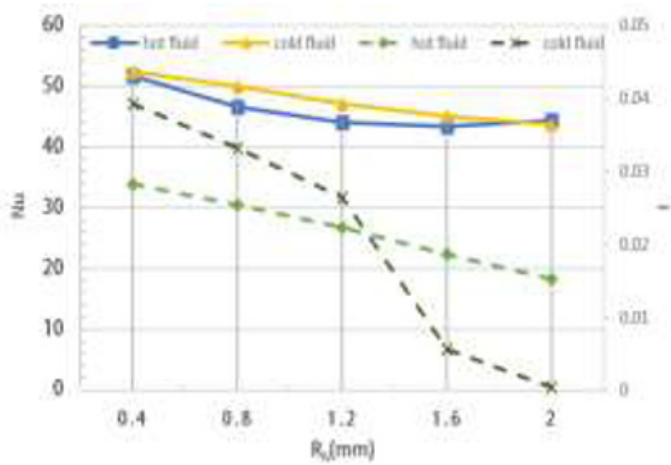

Figure 4. The effect of radium of the hot channel on the Nusselt number (denoted by solid lines) and fanning friction factor (denoted by dotted lines)

The effect of the radium of hot channel on the Nusselt number and fanning friction factor is shown in Figure 5. The results prove that the Nusselt number increases while the fanning friction factor decreases with the radium. The reduction of fanning friction factor has the same reason with that of hot channel radium. Although the heat transfer coefficient has a slightly drop therefore that the enlarged radium of cold channel and the reduced fluid dominate. According to eq.(7), the Nusselt number increases. 


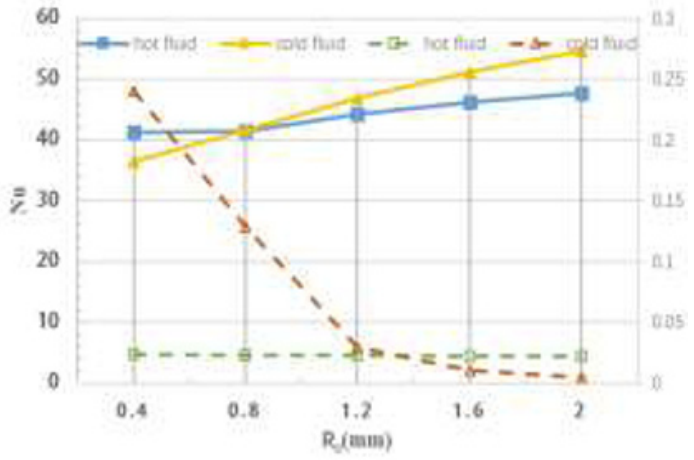

Figure 5. The effect of radium of the cold channel on the Nusselt number (denoted by solid lines) and fanning friction factor (denoted by dotted lines)

The important geometry parameters controlling the shape of channel include the amplitude and bend angle of the channel. Figure6 and Figure7 show the effect of the amplitude and angle on the Nusselt number and fanning friction factor respectively. In Figure 6, the amplitude changes from $1 \mathrm{~mm}$ to $5 \mathrm{~mm}$ in step of $1 \mathrm{~mm}$. It is indicated that the Nusselt number decreases with the amplitude, and the reason is that the lower heat exchange coefficient with higher amplitude. It is also indicated that fanning friction factor increases with the amplitude and the reason is that the higher amplitude leads to a longer flow length and larger mixing areas.

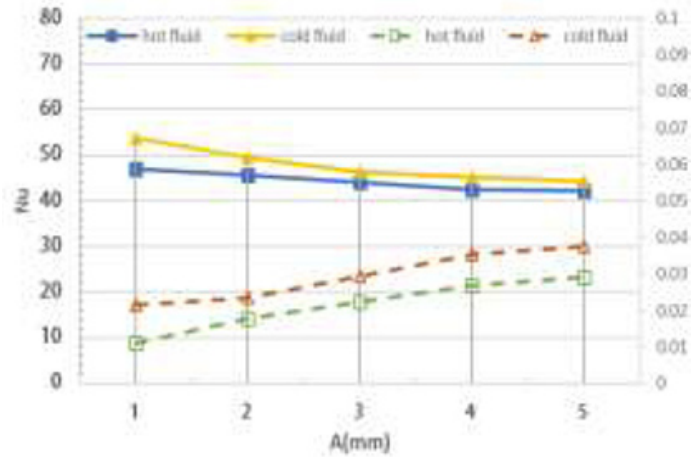

Figure 6. The effect of the amplitude of the channel on the Nusselt number (denoted by solid lines) and fanning friction factor (denoted by dotted lines)

In Figure 7, the pitch length changes from $10 \mathrm{~mm}$ to 50 $\mathrm{mm}$ in step of $10 \mathrm{~mm}$. It can be see that the Nusselt number increases with the growth of angle, which due to the higher mixing around the corners of channel. The Nusselt number of hot fluid is slightly less than that of cold fluid because of the lower Prandtl number in cold fluid. As for the fanning friction factor, it also shows a positive proportional to bend angle and the slope is much higher for cold fluid which causes that the friction factor of cold fluid becomes high than the hot one. It can be concluded to the higher mixing and the lower flow length.

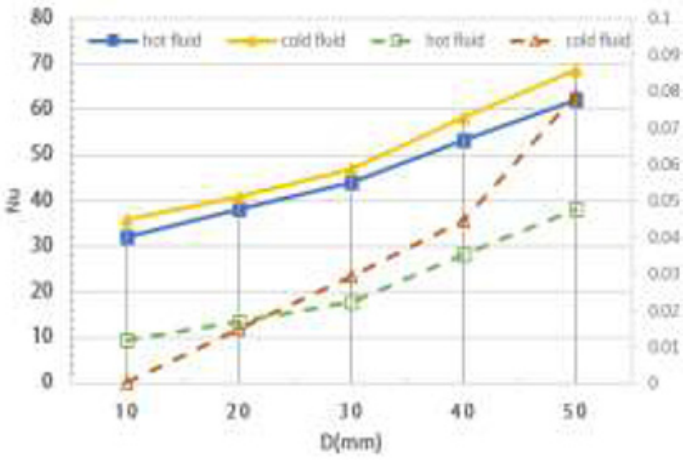

Figure 7. The effect of channel angles on the Nusselt number (denoted by solid lines) and fanning friction factor (denoted by dotted lines)

\section{Conclusions}

In this work, the five different materials are applied in sinusoidal channel PCHEs. The thermal-hydraulic performance and the structural analysis are investigated for those PCHEs with different materials. The thermalhydraulic performance for various channel diameters, channel amplitudes and channel angles. Based on the numerical results, the conclusions are drawn as followed.

(1) The materials have little effect on the thermalhydraulic performance, the maximum error between the Nusselt numbers and fanning friction factors are less than $4 \%$.

(2) The Nusselt numbers of sinusoidal channel PCHEs increase with the channel angle increase, the channel amplitude reduces, the channel diameter of cold fluid increase and the radium of hot fluid declines. Especially the channel angle has the maximum effect.

(3) The fanning friction factors of sinusoidal channel PCHEs increases with the channel angle increases, the channel amplitude increases, the channel diameter declines Especially the channel angle has the maximum effect.

\section{References}

1 J. Figley, X. Sun, S. K. Mylavarapu and B. Hajek, Progress in Nuclear Energy 68, 89-96(2013)

2 J. H. Kim, S. Baek, S. Jeong and J. Jung, Applied Thermal Engineering 30, 2157-2162(2010)

3 T. Ma, L. Li, X.-Y. Xu, Y.-T. Chen and Q.-W. Wang, Energy Conversion and Management 104, 5566(2015)

4 S. Jeon, Y.-J. Baik, C. Byon and W. Kim, International Journal of Heat and Mass Transfer 102, 867-876(2016)

5 A. M. Aneesh, A. Sharma, A. Srivastava and P. Chaudhury, International Journal of Heat and Mass Transfer 118, 304-315(2018)

6 I. H. Kim and H. C. No, Applied Thermal Engineering 31, 4064-4073(2011)

7 I. H. Kim, H. C. No, J. I. Lee and B. G. Jeon, Nuclear Engineering and Design 239, 2399-2408(2009)

8 J. Sung and J. Y. Lee, International Journal of Heat and Mass Transfer 115, 647-656(2017) 
9 N. Tsuzuki, Y. Kato and T. Ishiduka, Applied Thermal Engineering 27, 1702-1707(2007)

10 N. Tsuzuki, Y. Kato, K. Nikitin and T. Ishizuka, Journal of Nuclear Science and Technology 46, 403412(2009)

11 A. Meshram, A. K. Jaiswal, S. D. Khivsara, J. D. Ortega, C. Ho, R. Bapat and P. Dutta, Applied Thermal Engineering 109, 861-870(2016) 